
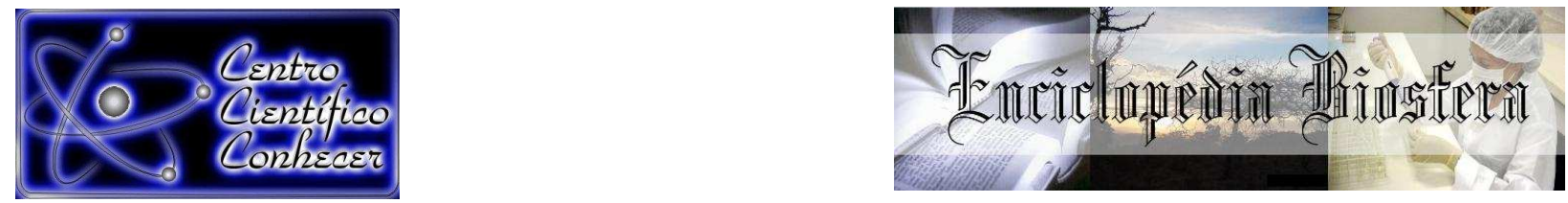

\title{
A “INVISIBILIDADE” DOS EMPREENDIMENTOS RESIDENCIAIS NA LEGISLAÇÃO DO ESTUDO DE IMPACTO DE VIZINHANÇA NA CIDADE DE GOIÂNIA - GO: UM ESTUDO DE CASO
}

Tauana Chaveiro de Araújo ${ }^{1}$, Antônio Pasqualetto ${ }^{2}$, Otniel Alencar Bandeira ${ }^{3}$, Obede Rodrigues Alves ${ }^{4}$ e Marcela Pimenta Faleiros dos Santo ${ }^{5}$.

${ }^{1}$ Graduada em Engenharia Civil pela pela Pontifícia Universidade Católica de Goiás - PUC Goiás.Goiânia, Brasil

${ }^{2}$ Coordenador Doutor do Programa de Pós- Graduação em Desenvolvimento e

Planejamento Territorial da Pontifícia Universidade Católica de Goiás - PUC Goiás.

${ }^{3}$ Mestrando em Desenvolvimento e Planejamento Territorial pela Pontifícia Universidade Católica de Goiás - PUC Goiás.Goiânia, Brasil

${ }^{4}$ Doutoranda em Ciências da Engenharia Ambiental pela Universidade de São Paulo USP, São Carlos, Brasil.(alves.obede@gmail.com)

${ }^{5}$ Mestranda em Desenvolvimento e Planejamento Territorial pela Pontifícia Universidade Católica de Goiás - PUC Goiás. Goiânia, Brasil

Recebido em: 08/09/2015 - Aprovado em: 14/11/2015 - Publicado em: 01/12/2015 DOI: http://dx.doi.org/10.18677/Enciclopedia_Biosfera_2015_059

\begin{abstract}
RESUMO
O Estudo de Impacto de Vizinhança (EIV) é um instrumento do Estatuto da Cidade que avalia o impacto de empreendimentos instalados no meio urbano que são causadores de impacto urbanístico e ambiental, conforme o Plano Diretor de Goiânia em que é aplicado. No caso específico da cidade de Goiânia, o EIV é exigido para empreendimentos institucionais e comerciais, mas não é exigido para construção de grandes projetos residenciais que assim como outros empreendimentos pode vir a causar impactos na vizinhança em que se situa. Objetivou-se neste trabalho mostrar a importância de se exigir o EIV para empreendimentos residenciais na legislação do município de Goiânia a partir de um estudo de caso sobre o empreendimento Residencial Viver Fama. O residencial possui área acima de cinco mil metros quadrados. Na execução do trabalho foi utilizada a metodologia de pesquisa e avaliação pós-ocupação, com aplicação de questionários que refletem as exigências ao EIV para os demais tipos de empreendimento na legislação do município. A ocorrência de impactos de vizinhança no empreendimento residencial foi confirmada. PALAVRA-CHAVE: Condomínios Residenciais, Impacto Urbano, Política Urbana, Sustentabilidade e Vizinhança.
\end{abstract}

\section{THE "INVISIBILITY" OF RESIDENTIAL DEVELOPMENTS IN LAW OF NEIGHBORHOOD IMPACT ON GOIÂNIA CITY - GO: A CASE STUDY}

\begin{abstract}
The Neighborhood Impact Study (EIV) is an instrument of urban policy that evaluates the impact of the implementation of projects considered to be of urban and environmental impact, according to the Plan Director city where it is applied. In the
\end{abstract}


specific case of the city of Goiania, the IVE is required for institutional and commercial projects, but is not required for approval of construction of large residential projects as well as other ventures may ultimately impact the neighborhood where it is located. This work had the initiative aimed to the need for EIV requirement for situated residential and governed by the laws of the city of Goiania - Goias with the case study on the project Residential Living Fame, which is a residential development with area above five thousand square meters. The execution of the work was used the methodology of research and evaluation of post-occupation with questionnaires that reflect the requirements for preparation of EIV for other types of enterprise in the municipal legislation. The occurrence of neighborhood impacts for residential development was confirmed.

KEYWORDS: Residential condominiums, Urban Impact, Urban Policy, Sustainability and neighborhood.

\section{INTRODUÇÃO}

A urbanização das cidades ocupa um aspecto que marca a civilização contemporânea. O Brasil praticamente se urbanizou nos últimos cinqüenta anos, isto é, tornar-se de um país rural em urbano. Cresceu não só o número de população das áreas urbanas, mas também o número e o tamanho das cidades em todo 0 território nacional, surgindo as metrópolis e o agrupamento urbano como reflexo da concentração espacial das atividades produtoras de emprego e de renda (ARAÚJO \& SILVA, 2003).

Existe uma acentuada preocupação da população, governantes, e entidades privadas em relação aos efeitos da ação do ser humano no meio ambiente. Com isso, torna-se indispensável, a realização de estudos para que o desenvolvimento urbano ocorra da forma mais sustentável possível, diminuindo o impacto no meio ambiente e reduzindo danos às populações e ao planeta. Em virtude desta preservação, pode ser necessário delimitar, ou até mesmo restringir, determinadas ações (SOARES, 2013).

O EIV é um instrumento que avalia os empreendimentos e atividades que causem grande impacto e/ou incomodidade. Porém, entre os casos em que o EIV é exigido na legislação do município de Goiânia, não estão incluídos os empreendimentos residenciais, que, porventura, também podem gerar impactos significativos (ALMEIDA, 2012).

Infelizmente o EIV não é exigido para empreendimentos residenciais em Goiânia, este cenário pode ser mudado com a ajuda de publicações de estudos científicos e estudos de casos. Neste sentido o objetivo deste trabalho é mostrar a importância do EIV para empreendimentos residenciais a partir de um estudo de caso sobre o empreendimento Residencial Viver Fama.

\section{Histórico do Estudo de Impacto de Vizinhança}

Nos anos 80, diante dos movimentos em defesa da reforma urbana, foi criado no Brasil, com a promulgação da nova Constituição da República de 1988 (BRASIL, 1988), um capítulo dedicado à política urbana. Foi uma inovação da Constituição o estabelecimento, pela primeira vez, de um capítulo específico para tratar da política urbana, contendo conjunto de princípios, responsabilidades e obrigações do Poder Público e de instrumentos jurídicos e urbanísticos a serem utilizados na proteção do meio ambiente natural e urbano, inclusive, com o intuito de diminuir as desigualdades sociais nas cidades, melhorando a qualidade de vida dos cidadãos (HELLER, 2011). 
O Município de São Paulo, por exemplo, prevendo a necessidade de estudos de impacto de vizinhança, a fim de evitar os impactos gerados pelos processos de desenvolvimento urbano sobre a vida dos habitantes, já trazia na Lei Orgânica, em 1990, a partir do art. 159, o Relatório de Impacto de Vizinhança (ALMEIDA, 2012). Segundo SCHVASBERG (2011) houve a necessidade de se definir uma nova classe de impactos, pois a legislação ambiental que trata dos impactos ambientais apenas previa a realização de Estudo de Impacto Ambiental e o respectivo relatório para empreendimentos urbanos de significativas proporções, tais como extensos conjuntos habitacionais e aeroportos, ou típicos de áreas rurais ou suburbanas, como, por exemplo, rodovias, ferrovias, barragens, exploração de minérios. Ocorre que os impactos decorrentes de ocupações de menor extensão no meio urbano, mas que possam causar vastas repercussões, tais como amplos supermercados, shopping centers, longos edifícios comerciais ou residenciais, também necessitavam de avaliações adequadas, considerando o local onde estão localizadas.

\section{Legislação}

O Estudo de Impacto Ambiental - EIA é previsto por ato normativo federal (CONSELHO NACIONAL DO MEIO AMBIENTE - CONAMA, 1986), uma vez que a Avaliação de Impacto Ambiental (AIA) é um dos instrumentos da Política Nacional do Meio Ambiente e os danos ambientais poderem alcançar proporções de âmbito regional ou nacional, sendo responsável por estabelecer as atividades e empreendimentos que necessitarão do estudo para obtenção de licenças.

Vale salientar que o artigo 97 do plano diretor, "A elaboração do EIV não substitui a elaboração e a aprovação de estudo prévio de impacto ambiental (EIA), requeridas nos termos da legislação ambiental." (GOIÂNIA, 2007, p. 30). O EIV deverá, obrigatoriamente, demonstrar, da forma mais clara possível, os prováveis impactos que a implantação do empreendimento ocasionará à vida e às atividades da população residente na vizinhança, assim como prever os efeitos sobre a infraestrutura pública local, de modo que a lista exposta no artigo 37 do Estatuto da Cidade não é exaustiva, mas meramente exemplificativa (SOARES, 2013).

Segundo CYMBALISTA (2001), o Estudo de Impacto de Vizinhança tem o poder de exigir alterações no projeto do empreendimento para a liberação da licença urbanística. Tais alterações podem incluir a diminuição de área construída, construção de novas vias de acesso, evitando a sobrecarga nas vias públicas existentes, o aumento no número de vagas de estacionamento, reserva de áreas verdes ou de uso comunitário no interior do empreendimento, medidas de isolamento acústico, recuos ou alterações na fachada, de modo a minimizar o impacto na paisagem urbana local, normatização de área de publicidade do empreendimento, entre outras.

\section{Importância do Estudo de Impacto de Vizinhança}

De acordo com COELHO (2001), os estudiosos dos impactos ambientais são obrigados, levando em consideração a urbanização e os vários problemas ambientais urbanos, a considerar os pesos variados da localização, topografia, distância, características geológicas, morfológicas, distribuição territorial, crescimento populacional, estruturação social do espaço urbano e processo de seletividade suburbana ou segregação espacial nas avaliações de impacto de vizinhança no meio urbano. Deve-se proceder desse modo porque os problemas 
ambientais (ecológicos e sociais) não atingem igualmente todo o espaço urbano, sendo muito mais frequentes nos espaços físicos de ocupação das classes sociais menos favorecidas. "O impacto de vizinhança diria respeito ao mau uso da propriedade vizinha e seus consequentes reflexos à incolumidade físico-psíquica das pessoas vizinhas, individualmente consideradas" (ROCCO, 2006).

Neste sentido, MEIRELLES (1996) entende que o proprietário ou possuidor do imóvel não pode usá-lo com abuso ou excesso na fruição de seus direitos, pois toda a utilização com excesso da normalidade, ou seja, fugindo aos padrões comuns de uso da propriedade segundo sua destinação e localização, é considerada mal uso, podendo ser impedida pelo vizinho por ser anormal.

O impacto de vizinhança, assim visualizado, não deixa de ser impacto ambiental, porém, no ambiente urbano sendo caracterizado não só por "qualquer alteração nas propriedades do ambiente, mas as alterações que provoquem 0 desequilíbrio das relações constitutivas do ambiente, tais como as alterações que excedam a capacidade de absorção do ambiente considerado (SOARES, 2013).

Entretanto, segundo CYMBALISTA (2001), os "impactos urbanos" devem ser considerados num contexto mais amplo. Devem-se levar em conta, impactos que ultrapassem aqueles sobre o sistema viário: ambientais (impermeabilização excessiva do terreno, aumento de temperatura), paisagísticos (impacto sobre paisagens de morros, dunas, vales, vista para frentes de água), econômicos (impactos sobre o comércio e serviços locais, ou sobre a produção de pequenos agricultores) e sociais (perda de empregos ou renda, sobrecarga de equipamentos públicos) (ALMEIDA, 2012). Como se pode observar tudo que cause dano à população afetada pelo empreendimento ou atividade deve ser considerado como impacto de vizinhança e, consequentemente, analisado no estudo, pois o objeto abrange os mais variados aspectos (ambientais, paisagísticos, econômicos, sociais, estruturais).

De acordo com SCHVASBERG (2011) o objeto do estudo deve abordar as repercussões da obra, edificação ou atividade na paisagem urbana do entorno, nas atividades humanas, na circulação de pessoas e mercadorias, assim como na infraestrutura urbana (água, esgoto, energia elétrica, comunicação, drenagem, vias, etc.) e nos recursos naturais da vizinhança (ar, vegetação, água, solo, silêncio, etc.).

No intuito de verificar se realmente haverá impacto ou não, faz-se necessário analisar se a infraestrutura existente é capaz de suprir a demanda criada pelo empreendimento. Da mesma forma, é preciso verificar a concorrência que um amplo empreendimento vai trazer para as atividades locais, em relação ao espaço, mercado, fornecedores, recursos humanos, clientela (COSTA \& MENDONÇA, 2012).

Nota-se a importância de identificar os elementos componentes da infraestrutura urbana, uma vez que sobre estes incidirão os impactos do empreendimento ou atividade implantada no local, devendo-se averiguar se essa infraestrutura terá capacidade para suprir a nova demanda criada pelos empreendimentos ou atividades de grande porte. Essa questão é de fundamental importância, pois se a infraestrutura local não suportar esse novo empreendimento ou atividade, surgirão duas situações: ou o empreendedor se obriga a complementar as redes de infraestrutura, de forma a ser possível o exercício da atividade, ou, em razão dos limites das redes e da impossibilidade de sua ampliação, o Estudo de Impacto de Vizinhança apontará para o impedimento da implantação do empreendimento no local, recomendando outra localização (HELLER, 2011).

Dessa maneira, se o EIV realmente analisar os pontos positivos e negativos 
do empreendimento ou atividade, no que diz respeito à influência na qualidade de vida dos moradores no entorno, as conclusões serão de suma importância para que obtenham a aprovação, podendo estabelecer várias condições ou contrapartidas para o funcionamento ou impedindo a realização, incluindo medidas mitigadoras, para prevenir ou abrandar possíveis danos e medidas compensatórias, a fim de reparar os danos ocasionados pelo empreendimento (ROCCO, 2006).

\section{Aspectos Avaliados no EIV}

Não há entendimento pacificado sobre a abrangência do termo vizinhança. Vários autores e mesmo textos legais consideram vizinhança das mais diversas formas, como dado número de quadras ou determinada metragem, intensidade do impacto, determinando a comunidade afetada ou, ainda, toda a comunidade que tenha a economia afetada pelo empreendimento ou atividade (ALMEIDA, 2012).

Em relação ao impacto sobre paisagem urbana e sobre atividades humanas da vizinhança, a maioria dos relatórios considerou como área de influência a quadra do empreendimento, as vias públicas lindeiras e os imóveis nela presentes. (ROCCO, 2006). Já em relação à definição do termo "vizinhança", diante das várias posições apresentadas, é possível depreender que, para melhor eficácia do EIV, deve-se atribuir ao próprio estudo a competência para definir qual a vizinhança afetada, tendo como ponto de referência os impactos e o alcance real, pois ela não pode ser tomada como uma área estática, pois depende da amplitude de cada empreendimento ou atividade e da abrangência dos impactos (LOLLO \& RÖHM, 2009).

O Estatuto da Cidade destaca em seu artigo 37 os aspectos mínimos que devem constar em um EIV, a saber: "adensamento populacional; equipamentos urbanos e comunitários; uso e ocupação do solo; valorização imobiliária; geração de tráfego e demanda por transporte público; ventilação e iluminação; e paisagem urbana e patrimônio natural e cultural" (GOIÂNIA, 2007, p. 75).

Segundo O PD a distribuição equilibrada, pelo tecido da cidade, dos equipamentos comunitários é fundamental para a sustentabilidade. A localização de cada equipamento na cidade, na região distrital ou no bairro deve obedecer a critérios de acessibilidade fundamentados na abrangência do atendimento social em relação à moradia (CHAMIÉ, 2010).

\section{MATERIAL E MÉTODOS}

O objeto deste estudo é o empreendimento Residencial Viver Fama, localizado na Av. Marechal Rondon, Setor Fama, na cidade de Goiânia, Goiás. O projeto conta com oito torres de 11 andares cada, totalizando seis apartamentos por andar de 70 metros quadrados cada, situado às margens da Avenida Marechal Rondon e ao lado do Córrego Capim Puba.

Foram realizadas visitas no período de 2013 a 2014 no setor Fama na vizinhança do Empreendimento Viver Fama com entrevistas aos moradores e comerciantes para observar o engajamento do empreendimento com a vizinhança e caracterizar os aspectos negativos e positivos desta interação, entrevistando moradores e comerciantes da área de influencia, conhecendo a opinião pública relativa ao empreendimento e as consequências da implantação do mesmo na região. 
Foram realizadas visitas ao órgão público Secretaria de Planejamento da Prefeitura de Goiânia (SEPLAN), para ter acesso a dados relativos aos aspectos geográficos da região, principalmente ao mapeamento da cidade no período de 2013 a 2014. Para coleta de dados necessários a realização deste estudo de caso, foi utilizada a metodologia de Avaliação Pós Ocupação, que é um processo sistemático e rígido de avaliação de empreendimentos, após a implantação, que tem como objetivo avaliar uma série de aspectos relacionados ao projeto e analisá-los separando os aspectos positivos e negativos do empreendimento $e$ as consequências para a região vizinha (HELLER, 2011).

Os foram alcançados com instrumentos de pesquisa como anotações, questionários, fotografias, para registro do objeto de estudo. Elaborou-se um questionário e aplicado com 40 residentes e profissionais atuantes no entorno do empreendimento residencial Viver Fama. O questionário foi composto por perguntas gerais (de 1 a 4 ) e específicas (5 e 6).

A questão número um (01) foi elaborada segundo a escala dicotômica, que oferece duas escolhas de resposta mutuamente exclusivas. O intuito desta questão foi conhecer a opinião da vizinhança do Viver Fama com relação à ocorrência ou não de impactos com a implantação do residencial.

A questão número dois (02) foi elaborada segundo a escala dicotômica, que oferece duas escolhas de resposta mutuamente exclusivas. $O$ intuito desta questão foi descobrir se a presença do residencial naquele local afetava a qualidade de vida da população.

A questão número três (03) que também foi elaborada segundo a escala dicotômica, tem como intuito saber se os vizinhos ao residencial Viver Fama concordam com a construção do mesmo na região.

A questão número quatro (04) foi elaborada segundo a escala dicotômica. Esta pergunta teve por objetivo descobrir se os vizinhos ao residencial gostariam de colaborar com a decisão do que é construído ou não na vizinhança.

\section{Análise de Estudo de Impacto de Vizinhança}

A questão cinco foi elaborada segundo escala numérica, que têm intervalos iguais que separam seus pontos, onde o respondente escreve um número na escala ao lado de cada item, juntamente com uma escala dicotômica, para classificar a resposta de escala numérica como positiva ou negativa. Baseou-se no artigo 37 do Estatuto da Cidade, que trata dos aspectos mínimos de análise em um EIV, para elaboração das questões, a saber: Adensamento Populacional; Equipamentos urbanos e comunitários (inclusão, qualidade, tempo de atendimento e disponibilidade); Equipamentos de transporte públicos da vizinhança; Uso e ocupação do solo; Valorização imobiliária; Geração de tráfego; Ventilação e iluminação; Paisagem urbana e patrimônio natural e cultural.

Os dados encontrados foram analisados e expressos em quadros e figuras na guia resultados e discussões.

\section{RESULTADOS E DISCUSSÕES}

Observa-se que a área onde se instalou 0 residencial era bastante permeável, próxima ao Parque Jerivá e Rio Meia Ponte. Atualmente as construtoras procuram locais próximos a áreas verdes para construírem os edifícios residenciais, pois o valor agregado aumenta. No entanto, este novo modelo de negócios tem causado profundos impactos ao meio ambiente, pois estas áreas permeáveis são 
pontos de recarga dos recursos hídricos superficiais e subterrâneos.

A Figura 1 mostra a imagem da área de estudo em 2013, antes do condomínio ser instalado; o traçado laranja representa a área onde ocorreu a pesquisa.

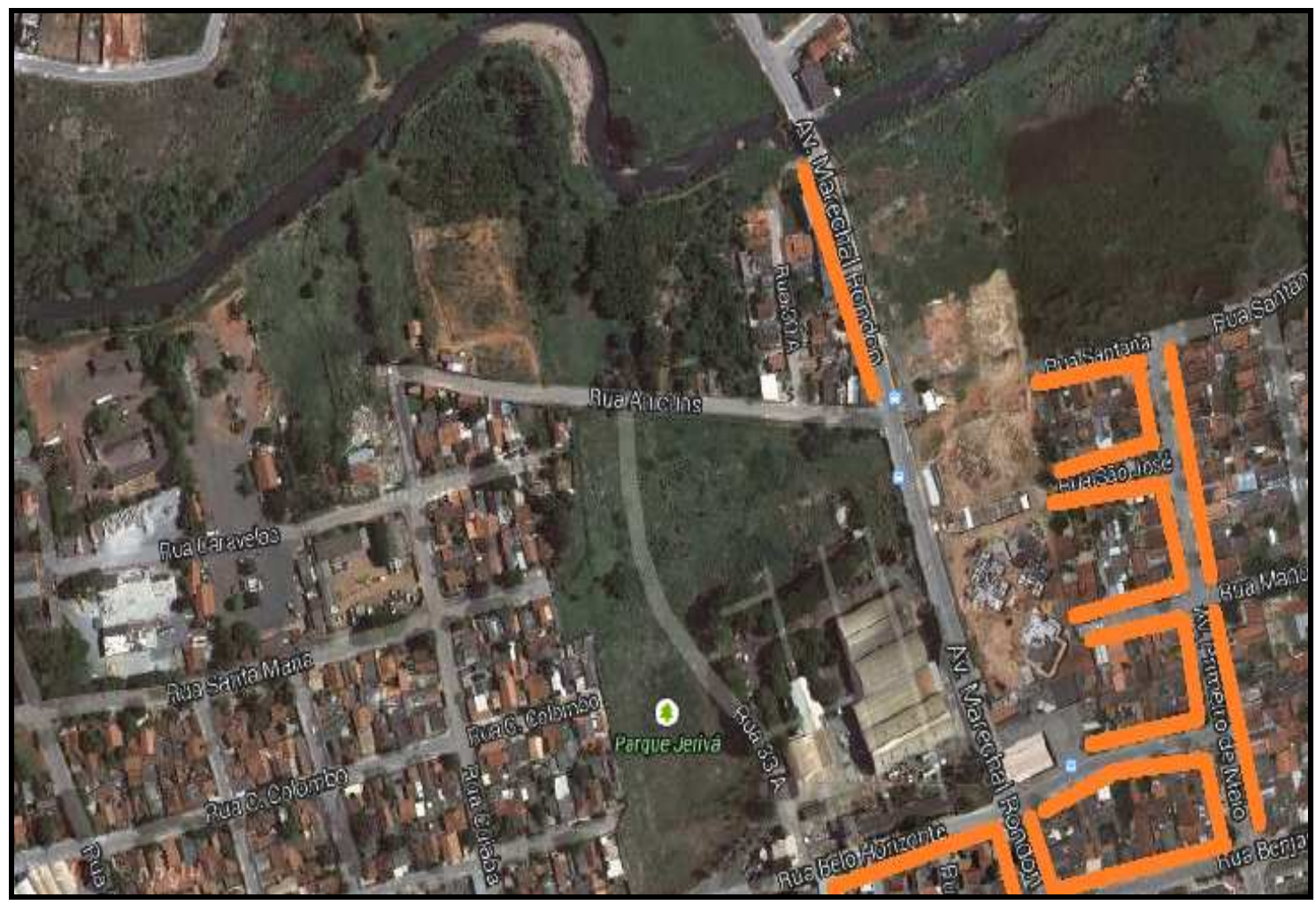

FIGURA 1 - Mapa de delimitação da área de realização da pesquisa Fonte: Google Earth, (2010) (adaptado pelos autores).

A preocupação com a avaliação de impactos surge com a sociedade contemporânea quando esta começa a sofrer danos com a redução e indisponibilidade dos recursos naturais juntamente com o crescimento desordenado das cidades, o aumento das desigualdades sociais e regionais, além da degradação das relações de vizinhança (SILVA \& LOLLO, 2013).

\section{Geração de Impactos de Vizinhança.}

De acordo com a pesquisa realizada, segundo os moradores e atuantes do entorno do residencial Viver Fama, 40\% dos pesquisados (16 pessoas) consideram que a implantação do residencial gera impactos de vizinhança em sua área de influência, os outros $60 \%$ não acreditam na geração de impactos de vizinhança pelo empreendimento em questão. Como mostra a Figura 2, uma parcela considerável da população vizinha, $75 \%$, consideram que a implantação do residencial afeta de alguma forma, seja de maneira positiva ou negativa, a qualidade de vida da vizinhança. 


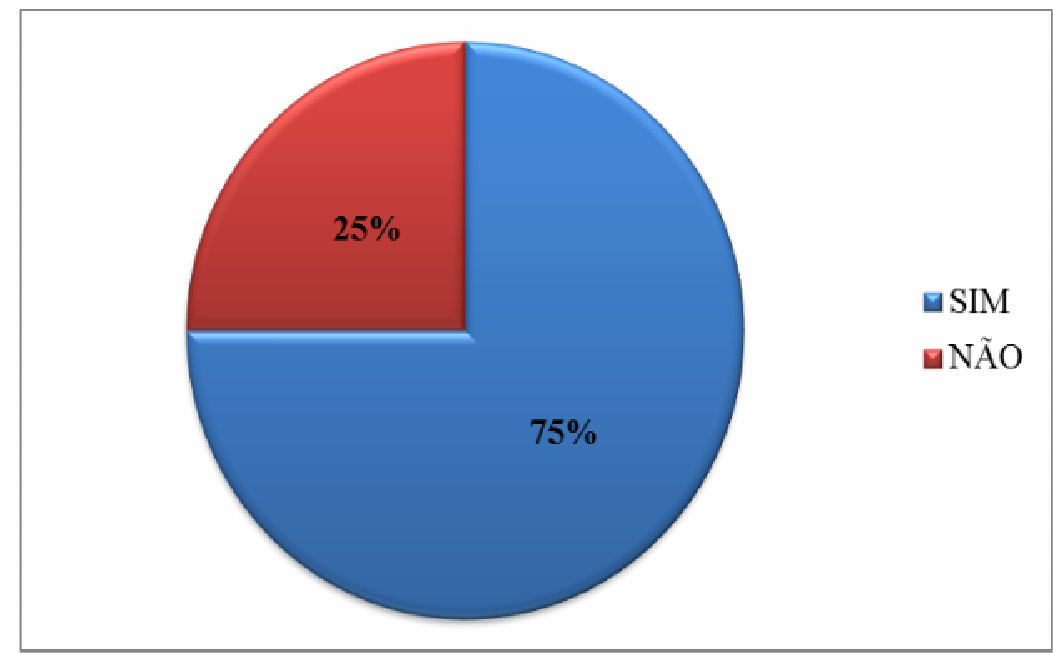

FIGURA 2 - Influência na qualidade de vida da população vizinha Fonte: Elaborado pelos autores com base na aplicação dos questionários

A questão número três mostrou que $90 \%$ da população vizinha pesquisada, 36 pessoas, concordam com a construção do Residencial Viver Fama no local em que foi implantado. A maioria dos entrevistados indicou que o fator crucial que torna positiva a implantação do condominio na vizinhança foi o fato de que anteriormente à instalação da residência, a vizinhança era considerada muito abandonada pelos governantes e exposta à criminalidade. Com a construção do residencial, a vizinhança ganhou mais visibilidade e segurança.

A Figura 3 mostra que $3 / 4$ da população pesquisada, $75 \%$, gostaria de contribuir na decisão do que deve ser construído na região em que mora, o que demonstra uma preocupação da população com as questões que geram impacto em sua área de influência.

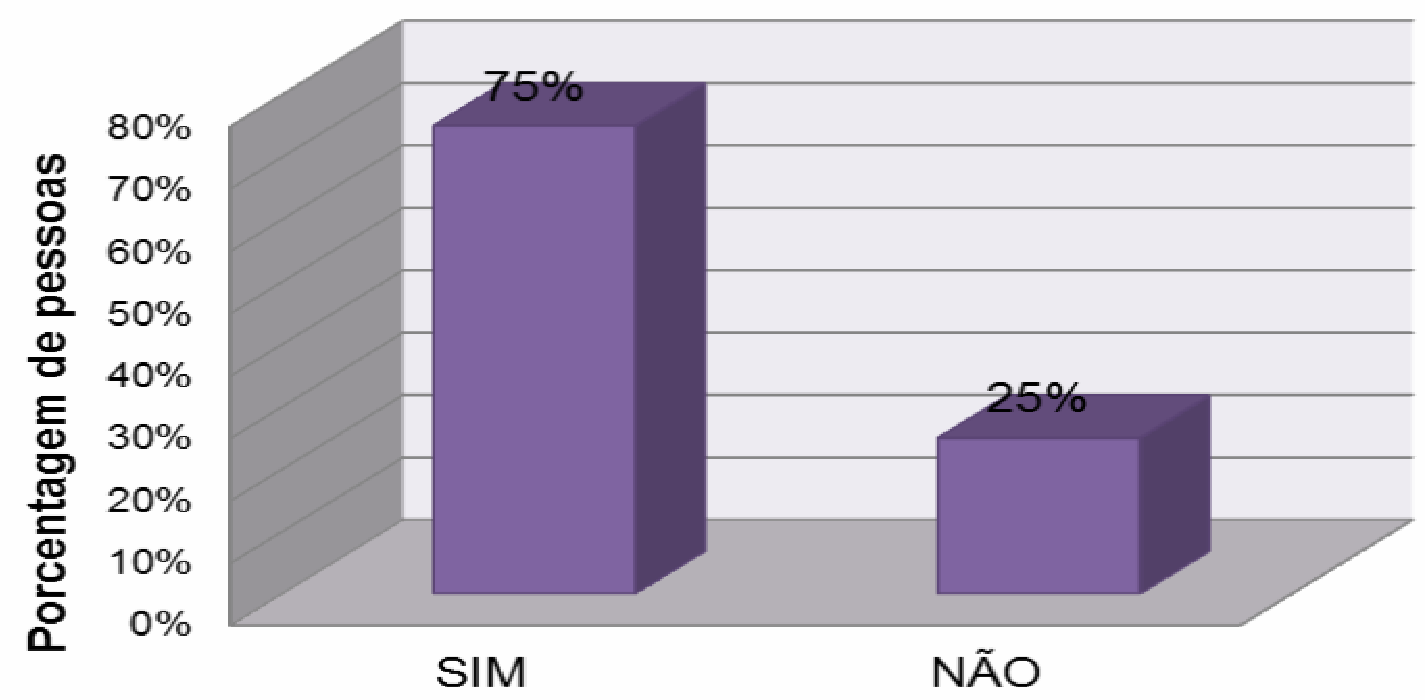

FIGURA 3: População que gostaria de colaborar com as decisões sobre as construções na região

Fonte: Elaborado pelos autores com base na aplicação dos questionários 
O Quadro 1 mostra a porcentagem de impactos de vizinhança indicados pela população com classificação entre:

- SEM IMPACTO: Porcentagem de ocorrências de nota zero no quesito;

- BAIXO IMPACTO: Porcentagem de ocorrências de notas entre 1 e 3 no quesito;

- MÉDIO IMPACTO: Porcentagem de ocorrências de notas entre 4 e 7 no quesito; e

- ALTO IMPACTO: Porcentagem de ocorrências de notas entre 8 e 10 no quesito.

QUADRO 1 - Porcentagem de impactos por categoria

\begin{tabular}{|c|c|c|c|c|}
\hline CATEGORIA & $\begin{array}{l}\text { SEM } \\
\text { IMPACTO }\end{array}$ & $\begin{array}{l}\text { BAIXO } \\
\text { IMPACTO }\end{array}$ & $\begin{array}{l}\text { MÉDIO } \\
\text { IMPACTO }\end{array}$ & $\begin{array}{l}\text { ALTO } \\
\text { IMPACTO }\end{array}$ \\
\hline Adensamento Populacional & 20 & 15 & 30 & 35 \\
\hline $\begin{array}{llll}\text { Inclusão de equipamentos urbanos } & \text { e } \\
\text { comunitários } & & & \\
\end{array}$ & 80 & 0 & 10 & 10 \\
\hline $\begin{array}{l}\text { Qualidade, tempo de atendimento e disponível } \\
\text { dos equipamentos públicos }\end{array}$ & 55 & 0 & 10 & 35 \\
\hline $\begin{array}{l}\text { Equipamentos de transporte públicos da } \\
\text { vizinhança }\end{array}$ & 60 & 5 & 5 & 30 \\
\hline Uso e ocupação do solo & 35 & 0 & 10 & 55 \\
\hline Valorização imobiliária & 15 & 10 & 30 & 45 \\
\hline Geração de tráfego & 25 & 15 & 15 & 45 \\
\hline Ventilação e iluminação & 80 & 5 & 0 & 15 \\
\hline $\begin{array}{l}\text { Paisagem urbana e patrimônio natural e } \\
\text { cultural }\end{array}$ & 35 & 0 & 20 & 45 \\
\hline
\end{tabular}

Fonte: Elaborado pelos autores com base na aplicação dos questionários

No Quadro 1 verifica-se que equipamentos urbanos e comunitários e ventilação e iluminação tiveram $80 \%$ sem impacto, ou seja, os itens de transporte público e ventilação e iluminação foram pouco afetados, na opinião dos entrevistados. Apesar de a maioria dos entrevistados acharem que não houve impacto significativo nestes dois aspectos avaliados, do ponto de vista do planejamento urbano, sabe-se que um empreendimento residencial do porte do Viver Fama impactará bruscamente o transporte público, a ventilação e iluminação local. Pode ser que estes incômodos apareçam após dois ou três anos, por isso é importante ter em mãos o EIV do empreendimento a fim de tomar medidas preventivas.

Já os aspectos de uso e ocupação do solo foram considerados de alto impacto com 55\% da opinião dos entrevistados. Conforme SILVA (2006):

Quanto à aplicação do Estatuto da Cidade (...) à ocupação do solo, organize a circulação e estabeleça medidas legislativas de respeito à convivência nas cidades, tendo por objetivo básico desenvolver da melhor maneira possível o que estabelece a Carta de Atenas, ou seja, dar aos cidadãos condições favoráveis de habitação, trabalho e lazer. (SILVA, 2006, p. 65). 
O uso e a ocupação do solo estão ligados aos aspectos econômicos e sociais de uma população, vez que a organização urbana na cidade deve ser justificável, ou seja, atender aos interesses da sociedade.

\section{Adensamento Populacional}

A Figura 4 refere-se aos conceitos atribuídos pelos residentes ao aspecto adensamento populacional.

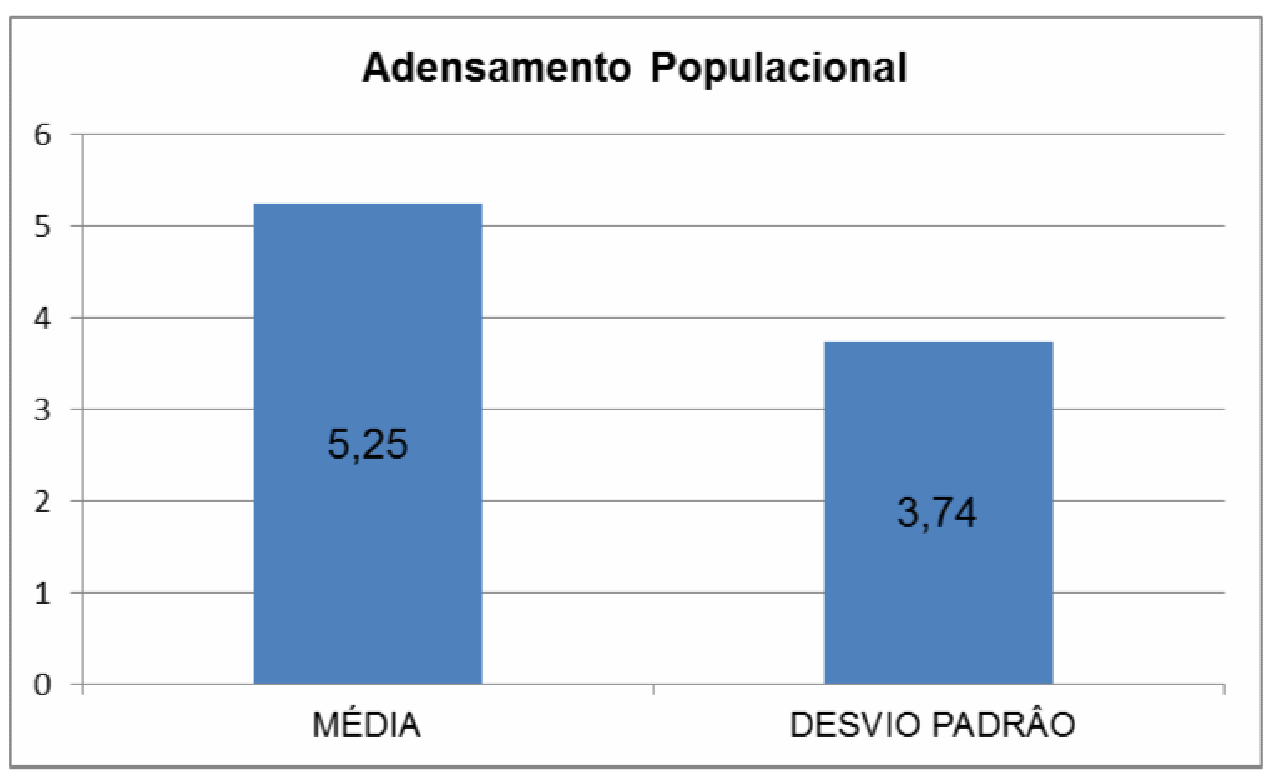

FIGURA 4 - Comparação de notas atribuídas pelos entrevistados ao item adensamento populacional em volta do residencial Viver Fama

Fonte: Elaborado pelos autores.

A nota média dada pela população para a ocorrência de adensamento populacional, incluindo atração de novos moradores, maior movimentação e fluxo de pessoas, foi de 5,25 , ou seja, um impacto mediano neste quesito. Cerca de $70 \%$ da população entrevistada acredita que o empreendimento causa impacto relacionado ao adensamento populacional, sendo que $80 \%$ consideram este adensamento populacional como positivo para a região. Segundo os próprios moradores, este fator é considerado positivo porque o bairro antes da chegada do residencial viver fama era abandonado e com índice de criminalidade elevada.

O caso do Residencial Viver Fama é apenas um exemplo de empreendimentos residenciais de grande porte que se instalam em determinados locais sem nenhum tipo de estudo de impacto de vizinhança. $O$ fator preponderante para os impactos causados por estes empreendimentos é o adensamento populacional, a partir desse aspecto outros são impactados e sobrecarregados.

\section{Equipamentos urbanos e comunitários}

A Figura 5 refere-se aos conceitos atribuídos pelos residentes ao aspecto equipamentos urbanos e comunitários. 


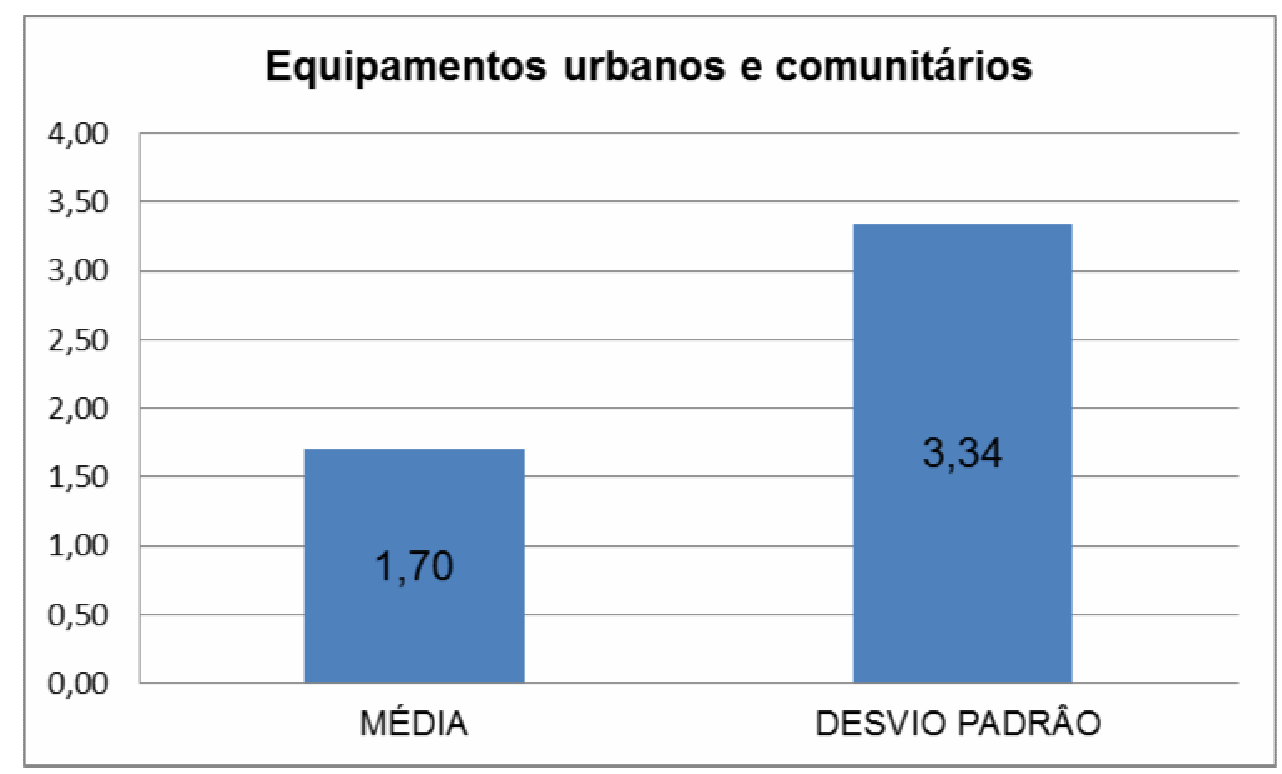

FIGURA 5 - Comparação de notas atribuídas pelos entrevistados ao item equipamentos Urbanos e comunitários em volta do residencial Viver Fama

Fonte: Elaborado pelos autores.

A nota média fornecida pela população para o impacto causado pela inclusão de equipamentos urbanos e comunitários foi de 1,70, ou seja, o impacto considerado pela implantação do novo residencial na região causou um impacto não muito significativo quanto a este quesito, o que significa que provavelmente não foram incluídos novos equipamentos urbanos e comunitários em função da construção do residencial Viver Fama, pois $80 \%$ dos pesquisados consideraram que não ouve impacto neste quesito.

Com relação à qualidade, tempo de atendimento e disponibilidade dos equipamentos públicos da região, a nota média atribuída pela população foi de 4,05. Sendo que $35 \%$ da população consideraram o impacto neste quesito como alto e negativo, trazendo incomodo para a população local. A ineficiência do planejamento urbano em Goiânia aliado à especulação imobiliária tem causado profundos problemas sociais e de infraestrutura na cidade. A não exigência do EIV para empreendimentos residenciais tem fortalecido os problemas já existentes e criado outros, paralelamente.

\section{Geração de Tráfego e demanda por transporte público}

A Figura 6 refere-se aos conceitos atribuídos pelos residentes ao aspecto equipamentos de transporte públicos da vizinhança. 


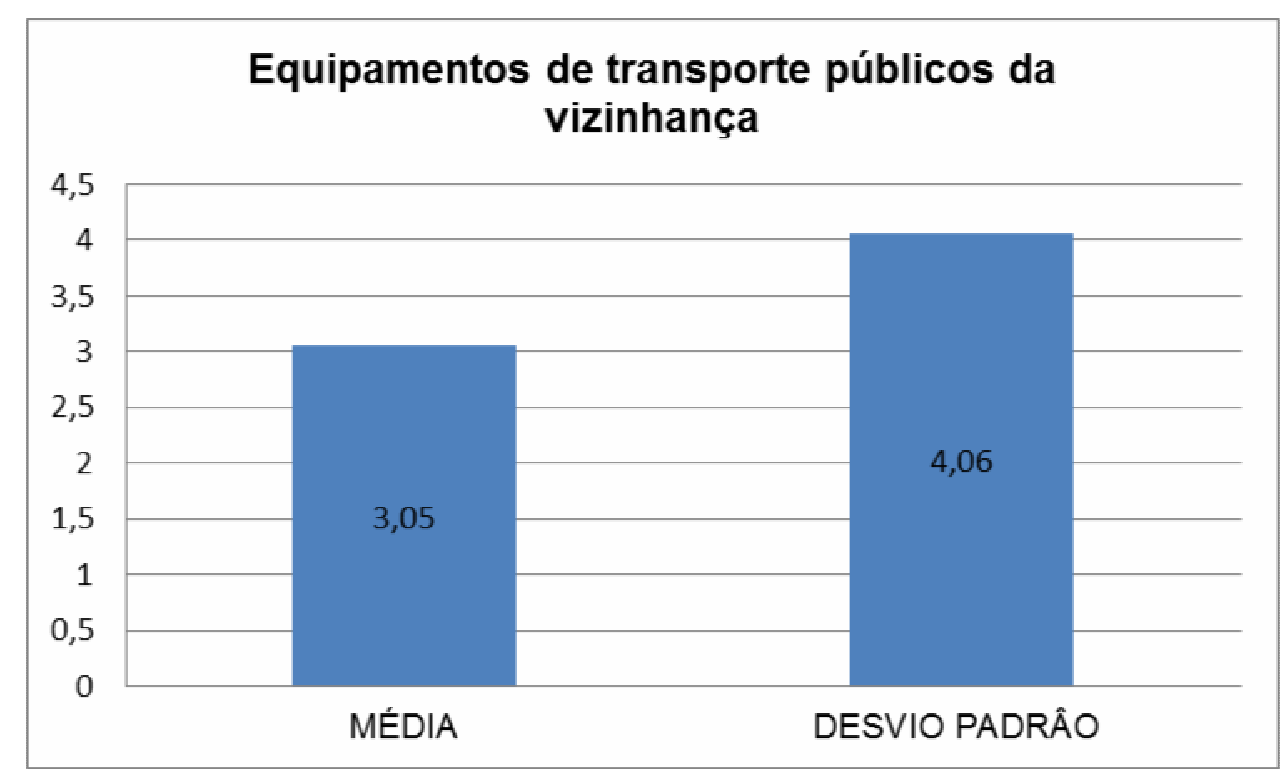

FIGURA 6 - Comparação de notas atribuídas pelos entrevistados ao item equipamentos de transporte públicos da vizinhança em volta do residencial Viver Fama

Fonte: Elaborado pelos autores.

A nota média atribuída pela população para o quesito de equipamentos públicos da vizinhança foi de 3,05, o que é confirmado pelo Quadro 1, sendo que $60 \%$ dos entrevistados não observaram impactos nos equipamentos de transporte publico. Os empreendimentos ou atividades geradoras de adensamento populacional geram incremento simultâneo na geração de tráfego e aumenta concomitante a busca por transporte público pela população (CARVALHO FILHO, 2006).

No quesito geração de tráfego, a Figura 7 a seguir ilustra a opinião da população, sendo que $40 \%$ dos entrevistados consideraram este impacto como positivo para a região.

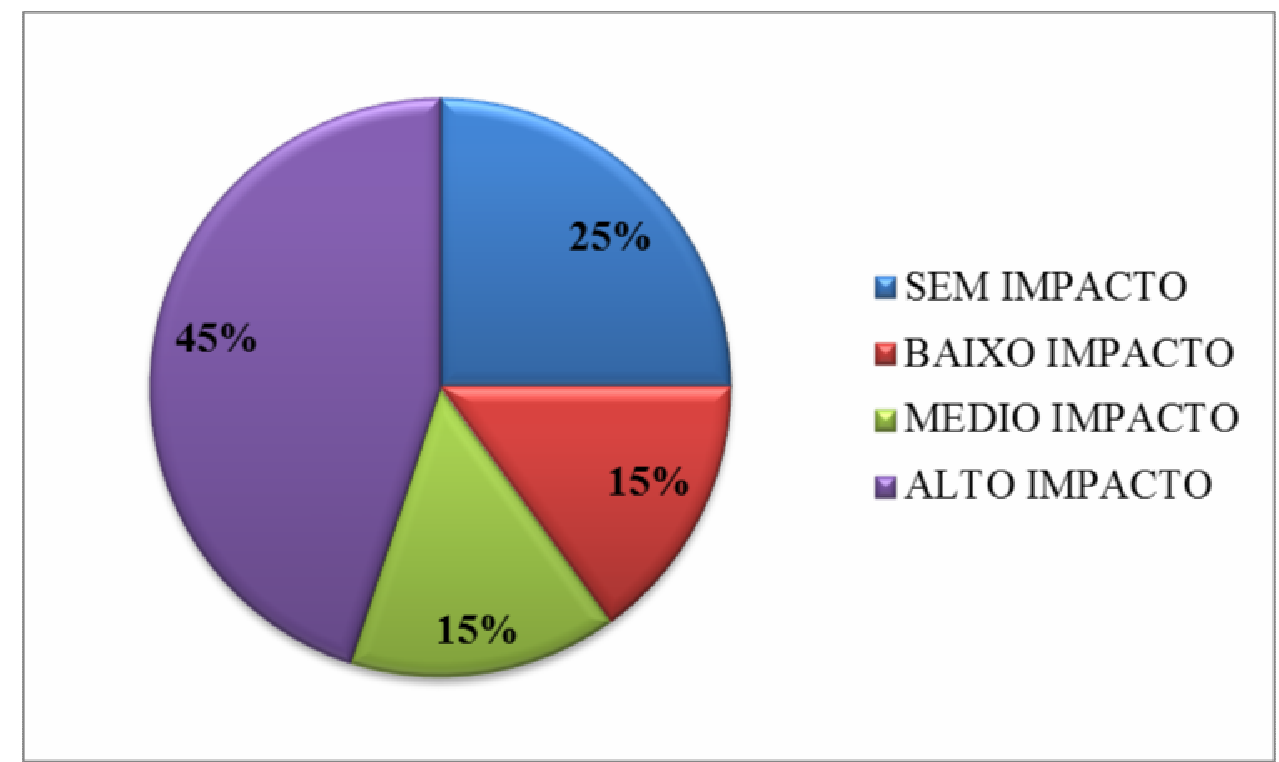

FIGURA 7 - Impacto causado pela geração de tráfego na região Fonte: Elaborado pelos autores com base na aplicação dos questionários 
Uma das grandes preocupações do planejamento urbano se refere à geração de tráfego e demanda por transporte público. A cidade precisa fornecer condições de deslocamento a todos os habitantes de forma eficiente e igualitária. Por isso é importante que o transporte público seja de qualidade e acessível a todos, e as vias urbanas sejam planejadas para atender as necessidades dos pedestres, ciclistas, motociclistas, carros, ônibus, caminhões e de todos aqueles que necessitem usá-la para sua mobilidade.

O local onde se instalou o Viver Fama está crescendo cada dia mais, outros edifícios residenciais já foram construídos ali próximo e atualmente é um desafio conciliar os diversos modais de transporte (carros, ônibus, motocicletas, bicicletas, a pé) nas vias públicas daquele lugar.

\section{Uso e ocupação do solo}

A Figura 8 refere-se aos conceitos atribuídos pelos residentes ao aspecto uso e ocupação do solo.

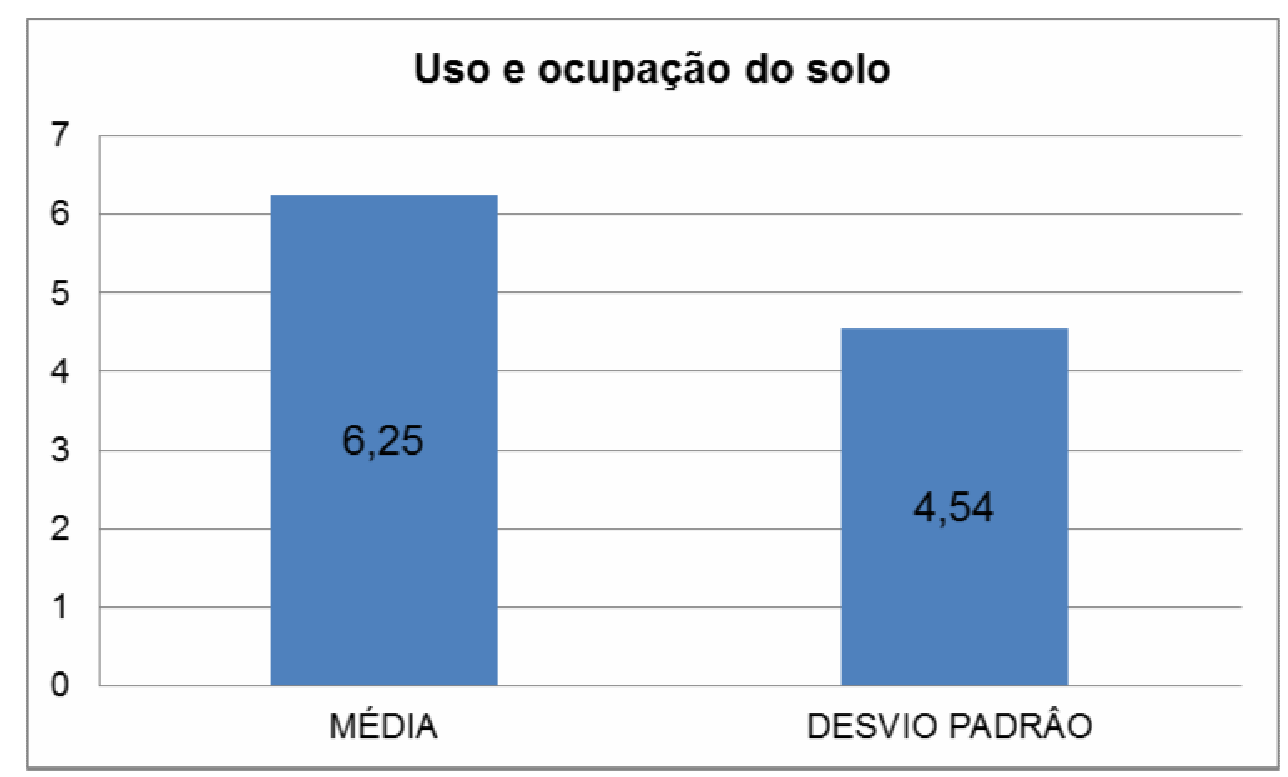

FIGURA 8 - Comparação de notas atribuídas pelos entrevistados ao item uso e ocupação do solo em volta do residencial Viver Fama.

Fonte: Elaborado pelos autores.

Com relação a este quesito, observa-se que $65 \%$ da população consideram os impactos causados pelo uso e ocupação do solo disposto pelo empreendimento é de médio a alto impacto, acumulando uma média geral que corresponde a 6,25.

\section{Valorização imobiliária}

O profissional que elabora o EIV deve deixar claro como ocorrerá a valorização ou desvalorização imobiliária nas imediações do empreendimento ou atividade. Deve indicar também as transformações urbanísticas que poderão ocorrer no local após a instalação da atividade ou empreendimento e principalmente as alterações socioculturais.

A Figura 9 refere-se aos conceitos atribuídos pelos residentes ao aspecto valorização imobiliária. 


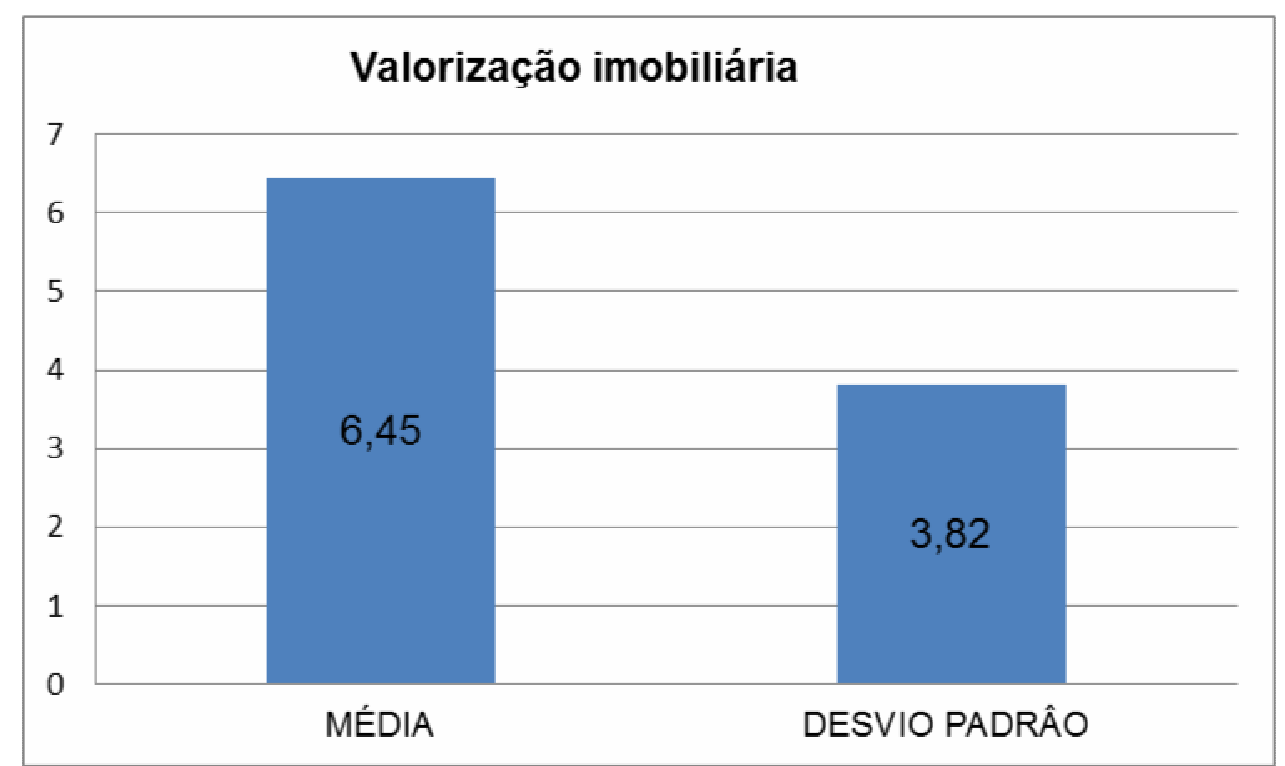

FIGURA 9 - Comparação de notas atribuídas pelos entrevistados ao item valorização imobiliária em volta do residencial Viver Fama

Fonte: Elaborado pelos autores.

Quando questionados sobre o quesito valorização imobiliária, a população classificou o impacto do residencial viver fama com 6,45 de média, sendo que $75,00 \%$ da população consideram como de médio a grande impacto (positivo).

\section{Ventilação e iluminação}

A Figura 10 refere-se aos conceitos atribuídos pelos residentes aos aspectos ventilação e iluminação.

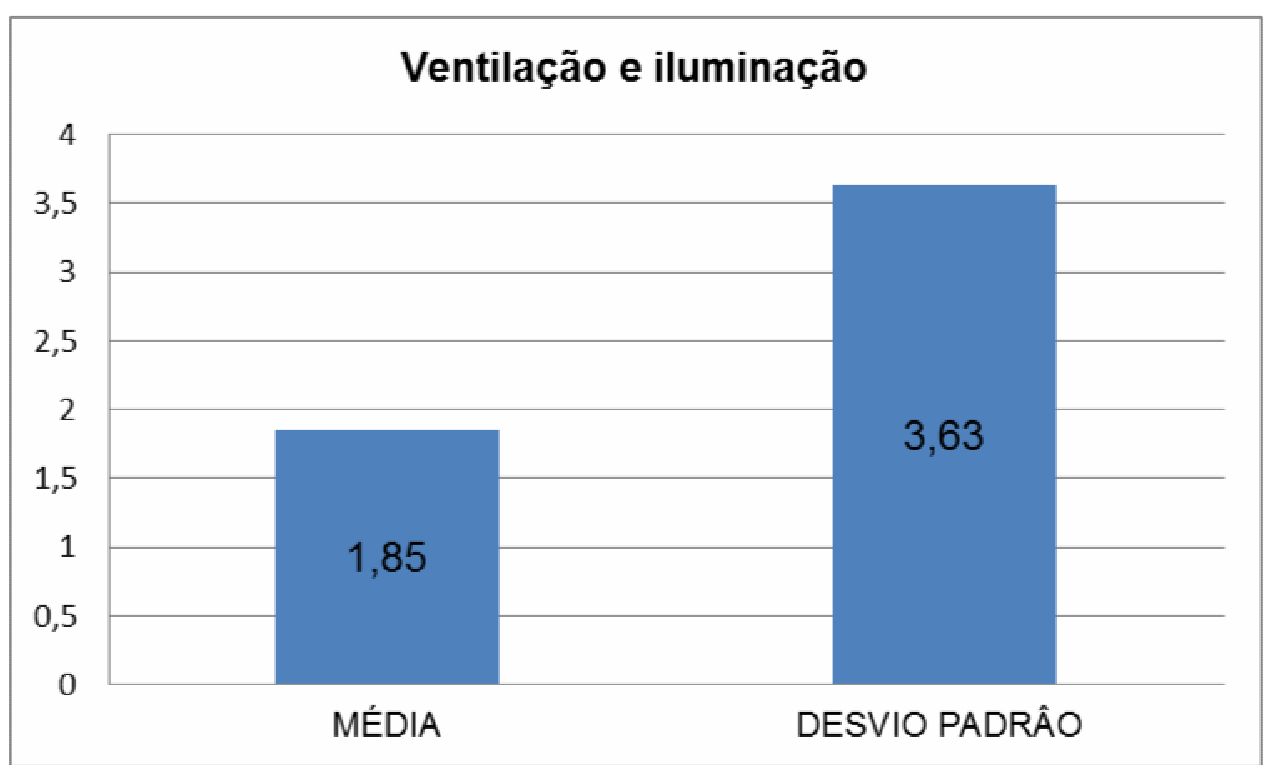

FIGURA 10 - Comparação de notas atribuídas pelos entrevistados ao item ventilação e iluminação em volta do residencial Viver Fama

Fonte: Elaborado pelos autores. 
De acordo com a população pesquisada, a nota média atribuída para impactos na ventilação e iluminação da região foi de 1,85 , ou seja, quase não foram encontrados impactos neste quesito.

Em regiões de clima tropical as correntes de ar que favorecem a ventilação urbana, podem ser facilmente alteras por construções volumétricas. O sombreamento excessivo de um terreno é prejudicial, favorecendo o desenvolvimento de fungos, podendo até mesmo interferir na saúde física e psíquica de seus usuários (SUNDFELD, 2006). Dependendo da técnica de construção e dos materiais usados em determinados empreendimentos é possível que os níveis de calor sejam intensificados na vizinhança imediata; a supressão da vegetação e a impermeabilização do solo são outros fatores que corroboram para isso. Este aspecto deve ser muito bem avaliado e exposto de forma clara e objetiva no EIV.

\section{Paisagem urbana e patrimônio natural e cultural}

A Figura 11 refere-se aos conceitos atribuídos pelos residentes ao aspecto paisagem urbana e patrimônio natural e cultural.

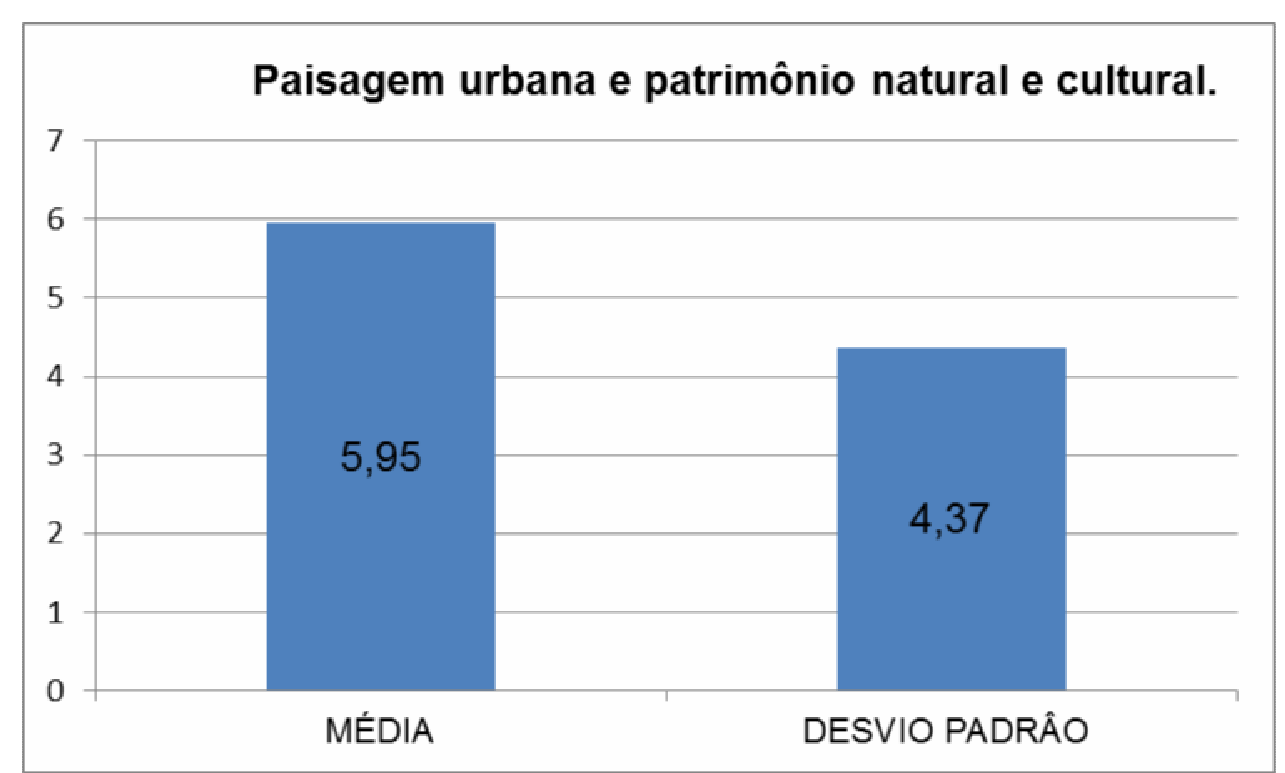

FIGURA 11 - Comparação de notas atribuídas pelos entrevistados ao item paisagem urbanos e patrimônio natural e cultural em volta do residencial Viver Fama

Fonte: Elaborado pelos autores.

Os entrevistados consideram um índice de $65 \%$ de impacto na paisagem urbana da região, sendo que $84,62 \%$ da população considerou este impacto como positivo, atribuindo uma nota de 5,95 (Figura 11). Segundo REIS (2011), na medida em que a cidade é disposta ou busca transformar-se por um urbanismo inclusivo, para que todos os integrantes da comunidade tenham livre acesso às funções básicas, realizar-se-á a função social da cidade e, para isso, o EIV é um instrumento de vital importância.

Entre os itens que se destacaram como de muito interesse pela população esta o item: Medidas de recuperação, mitigação e compensação dos impactos de vizinhança gerados, que foi citado por $70 \%$ dos pesquisados como muito relevante ENCICLOPÉDIA BIOSFERA, Centro Científico Conhecer - Goiânia, v.11 n.22; p.3487 2015 
para inclusão na legislação para elaboração de estudos de impacto de vizinhança. Este item é citado por CHAMIÉ (2010) como um dos itens de análise que não pode faltar em um EIV.

\section{CONCLUSÃO}

As mudanças urbanas em Goiás têm conduzido Goiânia aos mesmos erros já vivenciados pelos principais centros urbanos brasileiros. Há necessidade de criação de uma emenda na Lei 8.646 de 2008, que trata do EIV, para incluir os empreendimentos residenciais. Há necessidade também de alteração do artigo 94 do PD que desconsidera os empreendimentos residenciais causadores de significativos impactos no município de Goiânia.

Além das questões já especificadas, existem outras temáticas que necessitam ser exploradas no EIV para garantir a efetiva aplicabilidade do estudo. Algumas sugestões seria a definição dos limites de vizinhança para cada especialidade de empreendimento, considerando critérios pré-definidos para garantir que a área afetada seja realmente contemplada pelo estudo.

Os empreendimentos residenciais são causadores de significativos impactos de vizinhança e não há justificativa para deixar de exigir o EIV de tais empreendimentos. A legislação que trata do EIV em Goiânia encontra-se falha e está deixando de cumprir o direito de vizinhança que todo cidadão brasileiro possui legalmente, além disso, os planejadores da cidade estão desconsiderando as alterações que estes empreendimentos residenciais causam no espaço urbano, na cultura, na infraestrutura geral da cidade e demais aspectos que são avaliados em um estudo de impacto de vizinhança.

\section{REFERÊNCIAS}

ALMEIDA, E. Aspectos Gerais do Estudo de Impacto de Vizinhança, Curitiba, Universidade Federal do Paraná, 2012.

ARAÚJO, M. L. M.; SILVA, J. M. da. Estatuto da Cidade e o Planejamento UrbanoRegional, Revista Paranaense de Desenvolvimento, Curitiba, n. 105, p 57-74, jul/dez. 2003.

\section{BRASIL. Constituição da República Federativa do Brasil, 1988.}

CARVALHO FILHO, J. S. dos. Comentários ao estatuto da cidade: Lei no 10.257, de 10. 07. 2001 e medida provisória no 2220, de 04.09.2001. Editor: Rio de Janeiro, Lumen Juris, 2006.

CHAMIÉ, P. M. B. Contexto histórico, sob o enfoque urbanístico, da formulação e legalização do estudo de impacto de vizinhança. Dissertação (Mestrado em Arquitetura e Urbanismo)- Faculdade de Arquitetura e Urbanismo, Universidade de São Paulo, São Paulo, 2010.

COELHO, M. C. N. Impactos Ambientais em Áreas Urbanas-Teorias, Conceitos e Métodos de Pesquisa. In: Art line. (Org.). Impactos Ambientais e Urbanos no Brasil. Rio de Janeiro: Bertrand Brasil, v. 1, p. 1-28.2001. 
CONAMA. Resolução no 1, 1986. Licenciamento ambiental - Normas e procedimentos. Disponível em: <http://www.mma.gov.br/port/conama>. Acesso em Abril de 2013.

COSTA, H. S. M.; MENDONÇA, J. G. Novidades e permanência na produção do espaço da metrópole: um olhar a partir de Belo Horizonte. In: OLIVEIRA, F. L.; COSTA, H. S. M.; CARDOSO, A. L.; VAINER, C. B. (Org). Grandes projetos metropolitanos: Rio de Janeiro e Belo Horizonte. Rio de Janeiro: Letra Capital, 2012.

CYMBALISTA, R. 2001. Estudo de Impacto de Vizinhança, Dica №192. São Paulo, Instituto Pólis.

GOIÂNIA. Lei Complementar № 171, 2007. Plano Diretor de Goiânia. Disponível: www.goiania.go.gov.br. Acesso em Abril de 2013.

HELLER, D. Ampla Concepção De Regularização Fundiária: Um Caminho Para As Cidades Sustentáveis, Rio Grande do Sul, Pucrs, 2011.

LOLLO, J. A. ; RÖHM, S. A. Loteamentos e mecanismos de avaliação de impactos no Brasil. HOLOS Environment (Online), v. 9, p. 145-166, 2009.

MEIRELLES, H. L. Direito de Construir. 7 ed. São Paulo: Malheiros, 1996.

REIS, J. E. A. O papel dos estudos de impacto de vizinhança na construção da função social da cidade. Belo Horizonte: Veredas do Direito, v.8, n.15, p.97-110, 2011.

ROCCO, R. 2006. Estudo de Impacto de Vizinhança: instrumentos de garantia do direito às cidades sustentáveis, Rio de Janeiro, Rocco, $R$.

SCHVASBERG, B.. 10 anos do Estatuto: quem disse que ia ser fácil? In:Seminário 10 anos de Estatuto da Cidade. Brasília. Out. 2011

SILVA, J. A. da. Direito Urbanístico Brasileiro. São Paulo: Malheiros, Pag. 65, 2006.

SILVA, P. D. O. D'; LOLLO; J. A. O Estudo de impacto de vizinhança como instrumento para o desenvolvimento da qualidade de vida urbana. Holos Environment, v.13, n.2, 2013, p. 151.

SOARES, L. M. Estudo de Impacto de Vizinhança e o Estatuto da Cidade, São Paulo, 2013.

SUNDFELD, C. A. O estatuto da Cidade e suas diretrizes. In: DALLARI, A. A.; FERRAZ, S. (cords.). Estatuto da Cidade: Comentários à Lei 10.257/2001. São Paulo: Malheiros, 2006. 